\title{
FORMAÇÃO DOCENTE NA CULTURA DIGITAL
}

\author{
TEACHING TRAINING IN DIGITAL CULTURE
}

ENSEÑANZA FORMACIÓN EN CULTURA DIGITAL

\author{
Ana Valeria Barbosa da Silva \\ Doutoranda em Educação-Currículo PUC/SP. \\ E-mail: anavalbsilva@gmail.com \\ https://orcid.org/0000-0001-6894-4815 \\ Paulo Romaro \\ Professor doutor da Universidade de Taubaté. \\ E-mail: promaro@pucsp.br \\ Orcid: https://orcid.org/0000-0002-8477-1739 \\ Priscila Gabriela Costa \\ Mestre em Educação: Psicologia da Educação Pontifícia Universidade Católica de São Paulo. \\ E-mail: prigacosta@hotmail.com \\ Orcid: https://orcid.org/0000-0001-7661-1148
}

\begin{abstract}
RESUMO
O presente estudo busca identificar as razões que levam à evasão do curso EaD (Ensino a Distância) para formação de curadores, em uma $2^{\mathrm{a}}$ edição, fornecido por uma plataforma gratuita que reúne recursos digitais de aprendizagem para todas as etapas da Educação Básica e os classifica de acordo com critérios diversos como: disciplina, ano escolar e habilidades da BNCC. O referencial teórico utilizado mostra o contexto do Ead no Brasil, os questionamentos acerca da formação docente no ambiente tecnológico e as possíveis causas da evasão nos Ambientes Virtuais de Aprendizagem (AVA). A metodologia aplicada foi quantitativa na medida que por meio de tratamento de dados foram realizadas análises estatísticas e qualitativas na medida em que a pesquisa foi subsidiada por documentos, questionários e relatórios. Os sujeitos da pesquisa se constituíram de 318 cursistas, em âmbito nacional, inscritos para a formação analisada. Os resultados elencados se debruçam sobre a desistência parcial dos cursistas, dos quais189 participantes finalizaram o curso e 129 evadiram. As conclusões foram preliminares na identificação dos fatores que contribuíram para a evasão.
\end{abstract}

PALAVRAS-CHAVE: EaD. Curadoria. Evasão. Tecnologia.

\section{ABSTRACT}

The present study seeks to identify the reasons that lead to the avoidance of the Distance Education (Distance Learning) course for training curators, in a 2nd edition, provided by a free platform that gathers digital learning resources for all stages of Basic Education and classifies them according to diverse criteria such as: discipline, school year and BNCC skills. The theoretical framework used shows the context of Ead in Brazil, the questions about teacher training in the technological environment and the possible causes of evasion in Virtual Learning Environments (VLE). The applied methodology was quantitative as, through data processing, statistical and qualitative analyzes were performed, as the research was supported by documents, questionnaires and reports. The research subjects consisted of 318 course participants, nationwide, enrolled for the analyzed training. The results listed focus on the partial dropout of the course 
participants, of whom189 participants finished the course and 129 dropped out. The conclusions were preliminary in the identification of the factors that contributed to the evasion.

KEY WORDS: Distance Learning; Curatorship; Evasion; Technology.

\section{RESUMEN}

El presente estudio busca identificar los motivos que llevan a evitar el curso de Educación a Distancia (Aprendizaje a Distancia) para la formación de curadores, en una za edición, proporcionada por una plataforma gratuita que reúne recursos de aprendizaje digital para todas las etapas de Educación Básica y los clasifica según diversos criterios como: disciplina, curso escolar y competencias BNCC. El marco teórico utilizado muestra el contexto de Ead en Brasil, las preguntas sobre la formación docente en el entorno tecnológico y las posibles causas de la evasión en los Ambientes Virtuales de Aprendizaje (AVA). La metodología aplicada fue cuantitativa ya que, a través del procesamiento de datos, se realizaron análisis estadísticos y cualitativos, ya que la investigación se apoyó en documentos, cuestionarios e informes. Los sujetos de investigación fueron 318 participantes del curso, a nivel nacional, inscritos en la formación analizada. Los resultados enumerados se centran en la deserción parcial de los participantes del curso, de los cuales 189 participantes terminaron el curso y 129 lo abandonaron. Las conclusiones fueron preliminares en la identificación de los factores que contribuyeron a la evasión.

PALAVRAS-CLAVE: Aprendizaje a distancia (DE); Curaduría; Evasión; Tecnología.

\section{INTRODUÇÃO}

Estamos na segunda década do século XXI, e vivenciamos muitos questionamentos sobre: ensino, aprendizagem e suas metodologias. A literatura, os congressos e inúmeras publicações ao redor do mundo, debatem intensamente - embora nem sempre de forma sistemática- como atingir os objetivos de ensino e aprendizagem em contextos complexos da sociedade atual, imersos em tecnologia e com demandas para as quais ainda não há respostas.

Dentro das escolhas feitas sobre novas propostas, há algum tempo o ensino à distância (EaD) ${ }^{1}$ em ambientes virtuais de aprendizagem (AVA), vem se consolidando como uma alternativa viável para conciliar demandas diversas. Seja híbrido ou não, auto instrucional ou não; esse caminho se amplia em inúmeras formações.

Ocorre que nessa alternativa, que soluciona algumas questões como ampliar o acesso à formação dos sujeitos e mitigar a dispersão geográfica; são encontrados outros

\footnotetext{
1 No presente estudo adotaremos a terminologia: o EAD, o ensino à distância e não a EaD, a educação à distância. A justificativa para a escolha está no significado do termo, quando recorremos ao dicionário a diferença fica clara. (MICHAELIS, 2011). O curso de formação de curadores estudado é um Ensino à Distância que transmite um conhecimento e treina os cursistas para atuarem na plataforma de modo colaborativo. $O$ termo ENSINO está mais ligado às atividades de instrução e treinamento. O termo EDUCAÇÃO refere-se à prática, ao ato e ao processo de desenvolvimento do ser humano.
} 
obstáculos a superar como ambientes com pouco tempo de interação direta e a apropriação de habilidades no uso da tecnologia.

A internet é um grande "repositório" de materiais de todo o tipo que podem ser utilizados como recursos educacionais. Pensando na organização desses materiais, surge uma plataforma digital, gratuita, com o objetivo de apoiar professores e alunos no uso de Objetos Digitais de Aprendizagem (ODA) e na troca de experiências com a construção de uma rede de compartilhamento. Isso ocorre por meio da reunião de recursos digitais de aprendizagem para todas as etapas da Educação Básica e os classifica de acordo com critérios diversos, como disciplina, ano escolar e habilidades da Base Nacional Comum Curricular (BNCC).

A plataforma foi criada em 2013, a partir da iniciativa de instituições que objetivavam contribuir com a educação e a partir de 2019, conta com o apoio e participação de uma representativa universidade paulista. A ferramenta tem como objetivo facilitar o acesso e o uso qualificado de tecnologia nas escolas, tornando as práticas dos educadores mais dinâmicas, atraentes e interativas. Possui mais de 30 mil conteúdos pedagógicos digitais entre: planos de aulas, vídeos, games, animações, vídeo-aulas, infográficos, mapas e outros recursos selecionados da internet e classificados conforme os conteúdos curriculares.

Com isso criou-se uma Rede Nacional de Curadoria que tem como responsabilidades: estabelecer parâmetros de qualidade para curadoria, realizar a formação de curadores e promover campanhas de engajamento para curadoria de temas, que são considerados prioritários pela Rede. As atividades estão estruturadas como uma rede colaborativa que conecta secretarias estaduais e municipais de educação. Isso é possível, porque ela permite a customização da plataforma e do acervo para e pelas redes de ensino.

A atuação envolve mais de 20 secretarias estaduais de educação, que juntas constroem as estratégias de implementação do projeto e colaboram com um acervo compartilhado de objetos digitais de aprendizagem. Atualmente, a rede é composta pelos seguintes Estados: Acre, Alagoas, Amapá, Amazonas, Espírito Santo, Goiás, Maranhão, Mato Grosso, Mato Grosso do Sul, Minas Gerais, Pará, Paraíba, Paraná, Pernambuco, Rio Grande do Norte, Rio Grande do Sul, Rondônia, Santa Catarina, São Paulo e Sergipe, além do município de Fortaleza. Assim que uma nova rede customiza uma plataforma própria, alterando layout, conteúdo ou funcionalidades, ela começa a selecionar e aperfeiçoar 
novos conteúdos que passam a ser visíveis para todas as outras plataformas já customizadas, formando, assim, uma grande rede de curadores de conteúdo.

Antes que um ODA seja validado e comece a fazer parte efetivamente do acervo da plataforma, ele passará por um processo de curadoria. Neste processo, especialistas em diversas áreas analisam e validam cada ODA, considerando os temas de todos os componentes curriculares, etapas e modalidades da Educação Básica. Uma vez aprovados e disponibilizados na plataforma, os objetos digitais de aprendizagem (ODA), podem ser encontrados pelo sistema de busca simplificado por meio de palavra-chave ou utilizando os filtros: etapas, anos e modalidades ou disciplina (componente curricular).

O objetivo principal dessa rede para a formação de professores é o de oferecer o acesso a recursos digitais para que os docentes possam aprimorar suas práticas e dinamizar suas aulas.

A formação em curadoria de planos de aula e de ODA, envolve as áreas de Linguagens, Ciências Humanas, Matemática e Ciências da Natureza, ambientados na plataforma. Nesse curso, que busca formar profissionais capazes de encontrar recursos tecnológicos inovadores e inseri-los com o correto preenchimento dos metadados, são discutidas definições e critérios de curadoria, são conceituados objetos digitais de aprendizagem, vivenciando na prática o papel de um curador e refletindo sobre suas possibilidades de atuação. Assim, os curadores formados colaborarão para que os professores façam bom uso desses recursos em sala de aula.

O conteúdo do curso está disponível em um AVA, com atividades de correção automática, tarefas e fóruns mediados. Os módulos do curso são compostos por: textos, vídeo aulas, spots, infográficos, recursos interativos e a indicação de ferramentas digitais disponíveis na internet.

Em 2018, de janeiro a novembro, a plataforma registrou 2,3 milhões de usuários, alcançando o número de 55 mil novos cadastrados no site e 4 mil ODA curados. Nesse mesmo ano, formaram-se 136 cursistas no EaD sobre curadoria, que agora integram a Rede Nacional de Curadores.

\subsection{Delimitação do problema}

O curso para Formação de Curadores possui duas edições, que ocorreram em 
âmbito nacional, sendo a última em 2019 de 04 julho a 23 setembro.

O público do curso na segunda edição foi constituído por professores da educação básica ou técnicos educacionais indicados pelas secretarias municipais e estaduais parceiras, e por alunos de licenciatura e/ou pedagogia indicados pela Faculdade de Educação da universidade parceira no projeto. O número inicial de vagas para a segunda edição do curso foi de 330 participantes, distribuídos em seis turmas de até 55 alunos (50 para professores e/ou técnicos das redes públicas de ensino e 5 para alunos de graduação da universidade). As redes públicas de ensino indicariam os cursistas para 300 vagas e a Faculdade de Educação para as demais 30 vagas. Para cada turma foi previsto um mediador indicado pela universidade integrante do projeto. A segunda edição contou com 318 inscritos distribuídos em seis turmas mediadas. No gráfico 1, é demonstrada a distribuição dos cursistas por Estado. ${ }^{2}$

Gráfico 1: Distribuição dos cursistas por Estado

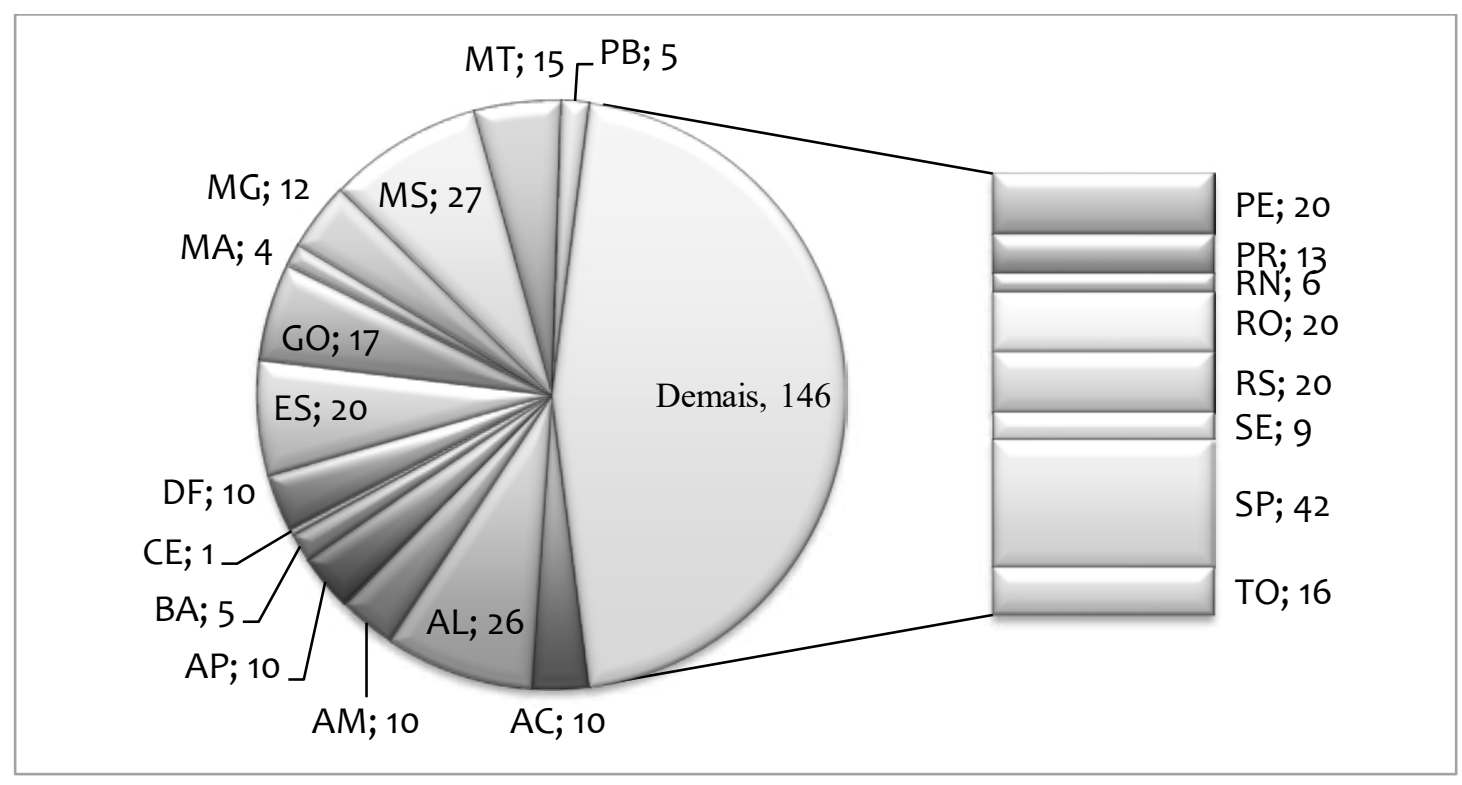

Fonte: Elaborado pelos autores, 2020.

Dos 318 inscritos, 29 não participaram de nenhuma atividade. Dos 289 cursistas restantes, 189 terminaram o curso e realizaram as atividades avaliativas, sendo 141 aprovados e 100 se evadiram em alguma etapa.

\footnotetext{
${ }^{2}$ Não há convênio com o Estado do Ceará, mas exclusivamente com o município de Fortaleza.
} 
O curso é totalmente gratuito e a distância, permitindo que o cursista possa administrar a sua participação conforme sua disponibilidade de tempo e horários. Acrescenta-se a isso que as turmas são apoiadas por uma área de suporte tecnológico e mediadas por profissionais que tem como missão esclarecer e orientar toda a condução pedagógica do trabalho.

A despeito desses e outros apoios disponibilizados, ao longo do curso a todos os cursistas, uma parcela significativa desses não chegou ao término do mesmo.

Dessa forma o objetivo geral desse estudo é identificar as razões que levaram à evasão do curso para formação de curadores, em sua segunda edição, tendo como objeto a Plataforma Digital.

Após a introdução ao tema, descrevendo o contexto pesquisado, a delimitação do problema, o objetivo, o objeto e os sujeitos da pesquisa; o presente texto está estruturado pela fundamentação teórica que aborda os temas EaD no Brasil, formação docente e evasão no curso EaD, a metodologia utilizada, os dados coletados e analisados e por fim a discussão dos resultados de modo a produzir proposituras passíveis de apropriação em contextos como o aqui pesquisado.

\section{FUNDAMENTAÇÃO TEÓRICA}

Este tópico estabelece um diálogo com autores que subsidiam o presente estudo abordando os temas EaD, formação docente e evasão.

\subsection{EAD no Brasil}

O ensino a distância no Brasil tem crescido significativamente. Conforme dados do Censo EAD.BR, em 2008 havia no país 2.648.031 alunos matriculados em EaD nos 1.752 cursos oferecidos. No Censo EAD.BR 2017 eram 7.773.828 alunos contabilizados, desses 1.320.025 em cursos totalmente a distância. Esse número cresceu para 9.374.647 no Censo 2018. Esclarecemos que o censo EAD abrange tanto cursos regulamentados, quanto cursos livres, corporativos e não corporativos (ABED, 2018).

Esse aumento se mostra significativo, porém não foi constante. Segundo o Censo EAD.BR 2017, a série histórica revela uma ascensão rápida do número de alunos em cursos 
dessa modalidade entre 2009 e 2012, quando foi criada a maioria das instituições formadoras em EaD, seguida de uma queda entre os anos de 2013 a 2015 e, desde então, com a flexibilização legal da oferta, uma nova e rápida ascensão em 2017 (ABED, 2017).

As bases legais para essa modalidade foram estabelecidas no Brasil pela Lei de Diretrizes e Bases na Educação Nacional $n^{\circ}$ 9.394, de 20 de dezembro de 1996, regulamentada pelo Decreto $n^{\circ} 5.622$ de 20 de dezembro de 2005, que revogou os Decretos $\mathrm{n}^{\circ} 2.494$, de 10 de fevereiro de 1998, e $\mathrm{n}^{\circ}$ 2.561, de 27 de abril de1998 com normatização definida na Portaria Ministerial $n^{\circ} 4.361$, de 2004.

Moran e Valente (2015, p.1), definem o EaD como o "processo de ensinoaprendizagem, mediado por tecnologias, onde professores e alunos estão separados espacial e/ou temporalmente." Para Nunes (1992), a separação física entre professor e aluno é a característica básica dessa modalidade de ensino, mediada por tecnologias, o que influencia a organização educacional, alterando seu planejamento, seu projeto político pedagógico e sua organização estrutural. Segundo Bokumus e Maia (2018), o Brasil, por sua extensão geográfica, favorece uma educação mediada por tecnologias que aproximam as pessoas, de todas as partes do país. Destaca-se um dado do censo de 2008 , que $42 \%$ dos estudantes matriculados em EaD estavam em outro estado que não aquele de origem da instituição de ensino na qual estudavam.

Assim, o EaD tem se tornado uma opção para que o conhecimento alcance indivíduos, tanto aqueles que moram em cidades grandes, quanto os que moram em vilas distantes dos grandes centros. O EaD não se limita ao espaço e ao tempo, mas oferece acesso às diferentes formações. Confirmando essa ideia, Litto (2008) dá seu parecer a respeito do EaD, afirmando que ele representa uma solução apropriada para o acesso de pessoas que não tiveram essa oportunidade anteriormente.

O EaD oferece algumas, levando muitos alunos a preferirem essa modalidade pois ela oferece flexibilidade, e livre administração do tempo de estudo. O baixo custo e a evolução acelerada da tecnologia são fatores que permitem que o ensino alcance os lugares mais distantes e pessoas que, de outra forma, dificilmente teriam acesso à educação (BOKUMUS; MAIA, 2018).

\subsection{Formação docente e EAD}


Diante do aumento da oferta de cursos a distância considera-se relevante tratar dos desafios detectados na formação dos professores nesse ambiente. Segundo Jesus e Maciel (2015, p. 144):

O crescente aumento de curso de formação de professores por intermédio da Internet tem revelado novas configurações na vivência desses profissionais na contemporaneidade. Docentes são quase sempre peremptoriamente convidados a se debruçar nos labirintos da cibercultura que os seduzem pela aparente praticidade de estudar diante dos computadores. Contudo, apesar dessa comodidade, profissionais da educação, cada vez mais, são desafiados a lidar com novas práticas de letramento digital que perpassam pela flexibilização da gestão do tempo, do espaço e das atividades educacionais propostas.

Ainda segundo Jesus e Maciel (2015), os educadores necessitam de oportunidades que os envolvam em situações de estímulos para explorar a tecnologia digital, a identificar suas potencialidades e a refletir sobre suas ações. Assim o educador poderá compreender sua experiência relacionando-a com teorias que o ajudem a superar o nível intuitivo da ação docente. Dessa forma quando oportunizado com atuações em contextos práticos, possivelmente vislumbrará reconfigurações que propiciem processos de reculturação e/ou reestruturação de suas práticas docentes em ambientes virtuais de aprendizagem (PINOTTI, 2010).

O conceito de reculturação de práticas docentes que Fullan (2012) expõe, engloba o processo em que professores precisam desenvolver novos valores, crenças e normas para que a construção de novas percepções sobre suas práticas pedagógicas, sejam possíveis. O autor ainda enfatiza os aspectos de reestruturação, que perpassam por mudanças nos papéis, estruturas e outros componentes que possibilitam a formação de novas culturas (FULLAN, 2012). A nova forma de estruturar o tempo no cotidiano escolar, objetivando a aquisição de novos valores advindos de processos de reculturação, pode indicar uma reorganização temporal de práticas docentes. Para exemplificar a reculturação, Jesus (2007, p.5) afirma:

Os alunos iniciantes em cursos a distância podem trazer práticas interacionais típicas dos diferentes contextos sociais nos quais eles já vivenciaram. No caso dos professores, especialmente, carregam uma cultura específica da sala de aula. São eles que corrigem e dão permissão para quem deve falar, por exemplo. Entretanto, no mundo digital a dinâmica de uma sala de aula pode diferir muito das experiências outrora vividas pelos alunos, solicitando aos discentes e aos docentes que se 
reculturem ao novo contexto de aprendizagem. Talvez essa seja uma das razões que levam alguns alunos a viver situações de extensa dificuldade, como compreender o espaço do curso, interagir nas salas de aulas digitais, organizar seu tempo diante das demandas do curso. Outros, pelo contrário, aprendem a se comunicar nesse ambiente, adaptando-se ao novo contexto, anteriormente desconhecido.

Os professores formados no paradigma tradicional são impelidos a apreender uma nova cultura, muitas vezes distante da sua realidade cotidiana, portanto complexa e multifacetada (JESUS, 2007). Há de se considerar a formação de professores para o desenvolvimento de currículos e projetos pedagógicos, em que as tecnologias da informação e da comunicação não representem apenas ferramentas, mas recursos instituintes de novas formas de aprender e ensinar, na perspectiva das redes colaborativas e da autonomia dos sujeitos (PINOTTI, 2010).

\subsection{Evasão nos cursos de EAD}

Segundo os dados do Censo as taxas de evasão nos cursos à distância, estão cada vez mais próximas das taxas dos cursos presenciais. Mas, segundo esse mesmo documento, as taxas de evasão são sempre uma preocupação em qualquer nível e área de ensino, e o EaD não é uma exceção. Ainda segundo o censo, menos de 50\% das instituições conhecem os motivos dessas evasões, que hoje se constituem índices de 26\% a 50\% (ABED, 2018).

Holder (2007) indica que um aluno de sucesso no ensino on-line deve possuir certas habilidades de aprendizagem que não são essenciais ao ensino presencial. Algumas características peculiares do ensino on-line podem ajudar a explicar estes números. No EaD, o estudante é corresponsável pelo seu processo de aprendizagem, construindo conhecimentos e desenvolvendo uma autonomia, atitudes e hábitos relativos ao estudo, à profissão e a sua própria vida, no tempo e no local que se adequam a sua rotina, sem a participação em tempo integral de um professor. Assim, professor e/ou tutor é um mediador deste processo, auxiliando no processo de aprendizagem do estudante, ajudando-o a se organizar temporalmente para permanecer atento às necessidades dos saberes de cada disciplina e incentivando-o a interagir com o grupo. Para desenvolver esta 
mediação, ele conta com o apoio de AVA, com materiais didáticos intencionalmente organizados e apresentados em diferentes suportes de informação.

Segundo Santos e Neto (2009), a evasão é tratada como a desistência definitiva do estudante em qualquer etapa do curso. Pesquisas buscam entender e explicar suas possíveis causas, de forma a propiciar ações corretivas e preventivas em relação à evasão. Santos e Neto (2009), reuniram quatro autores que tratam da evasão sob diferentes perspectivas elencadas a seguir.

Para Coelho (2002), as principais suposições sobre a evasão nos cursos são o insuficiente domínio técnico do uso do computador, a inabilidade em lidar com as novas tecnologias que criam dificuldades em acompanhar as atividades propostas pelos cursos à distância. Soma-se a isso a relação presencial entre professor e alunos, pois neste tipo de relacionamento julga-se haver maior interação e respostas afetivas entre os envolvidos no processo educacional. A ausência de reciprocidade da comunicação, ou seja, dificuldades em expor ideias numa comunicação escrita a distância, inviabiliza a interatividade; e a falta de um agrupamento de pessoas numa instituição física, construída socialmente e destinada, muitas vezes, à transmissão de saberes.

Tresman (2002), também buscou evidenciar as principais razões que levariam ao abandono de um curso a distância. Elencou: o custo do curso, a incerteza de ter tempo em se comprometer com o curso, mudanças na vida pessoal e dificuldade de fazer a escolha entre diversas opções.

Shannon e Bylsma (2006) enumeram fatores relacionados ao estudante, à família e à comunidade que podem influenciar a evasão, bem como fatores relacionados à instituição de ensino, destacando algumas circunstâncias possíveis: questão socioeconômica, realização acadêmica insuficiente, cursos com poucos encontros presenciais, diversas disciplinas com reprovações, doença na família, falta de um currículo relevante, estratégias instrucionais passivas, uso inadequado da tecnologia e desrespeito aos estilos de aprendizagem dos estudantes.

Ainda, em relação aos fatores que historicamente afetam os níveis de evasão em cursos universitários a distância, Xenos, Pierrakeas e Pintelas, (2002) os dividem em três grandes categorias: 1) fatores internos relacionados às percepções do aluno; 2) fatores relativos ao curso e aos tutores; 3) fatores relacionados a certas características demográficas dos 
estudantes, como idade, sexo, estado civil, número de filhos, tipo de trabalho ou profissão, entre outras.

Observa-se que as possíveis causas são decorrentes de múltiplos fatores, sejam eles pessoais, institucionais ou decorrentes do atual sistema educacional vigente. De acordo com Yorke e Longden (2004), existem duas abordagens de pesquisa utilizadas para entender o processo de evasão: quantitativa e qualitativa.

A abordagem quantitativa envolve a análise dos dados educacionais para evidenciar possíveis correlações entre a evasão e múltiplos indicadores. Esta abordagem suporta decisões políticas em um nível macro e pode ajudar a melhorar a eficiência e eficácia do sistema ou instituição. A abordagem qualitativa pode ser empregada em uma escala menor e tem como objetivo compreender o fenômeno sob o ponto de vista de um grupo de indivíduos. Os métodos de coleta, utilizados nesta abordagem, são entrevistas. $\mathrm{Na}$ presente pesquisa, o processo de evasão é estudado na abordagem quantitativa e qualitativa, analisando o relatório e os dados fornecidos pela instituição que atua na gestão e construção da formação e evidenciando as possíveis correlações entre a evasão e os diversos indicadores.

\section{METODOLOGIA}

A presente pesquisa objetiva identificar fatores que resultaram na evasão do curso de formação de curadores, que é o nosso objeto, sendo os cursistas integrantes da segunda edição, ocorrida em 2019, os sujeitos analisados. Após a identificação do objeto desta pesquisa e seus sujeitos, foi delimitado o problema a ser investigado e seu contexto, assim como o planejamento para execução da mesma.

A natureza desta investigação é descritiva, com uma abordagem quantitativa e qualitativa. A análise quantitativa buscou por meio da codificação, tratamento e análise dos dados construir de modo fundamentado e confiável os resultados e discussões demonstrados. A abordagem qualitativa foi usada na análise documental de relatos dos sujeitos pesquisados. Essas abordagens são apoiadas nos fundamentos descritos por Chizzotti (2017, 2018) e por Creswell (2014).

Foi estabelecido contato com as instituições envolvidas para obter junto a seus representantes as aprovações necessárias mediante a descrição do projeto e respectivos 
objetivos. Nesse momento foi realizada uma entrevista com os coordenadores da instituição gestora para identificação de hipóteses e levantamento de dados qualitativos iniciais. Duas ações ocorreram em paralelo: uma foi à busca pelos dados que subsidiariam a análise e a outra foi à pesquisa no Portal de Periódicos da Coordenação de Aperfeiçoamento de Pessoal de Nível Superior (CAPES) por publicações que abordassem os temas correlatos nesta pesquisa. As buscas foram construídas por meio das equações: EAD AND Brasil, com limitação temporal dos últimos dois anos (2017 a 2019), EAD AND evasão AND formação, com limitação temporal dos últimos dez anos (2009 a 2019), em português e seleção de artigos peer review (revisados por pares). Para ampliar os resultados encontrados foi utilizada a estratégia backward search ou busca para trás (OKOLI, 2019), que inclui na seleção as fontes citadas nos textos inicialmente selecionados.

De posse dos dados fornecidos, a saber: planilhas de notas, de Estados de localização dos cursistas, de pesquisa de satisfação e de etapas realizadas pelos alunos; além do relatório final; foi iniciado o tratamento dos dados e análise dos conteúdos.

A ação inicial foi unificar as quatro planilhas, que traziam dados qualitativos e quantitativos, em um único documento. Ato contínuo alguns dados foram codificados em 1 e o (variável dummy) ${ }^{3}$, como: se o cursista foi certificado ou não; se concluiu o curso ou não e se o cursista era aluno da faculdade de educação selecionada ou não.

Os intervalos de quantidades de horas investidas pelos cursistas para a realização das atividades também foram tratados conforme média dos intervalos de tempo disponibilizados nas alternativas do questionário. Esses procedimentos se fizeram necessários para a construção de uma análise que pudesse quantificar alguns dados e estabelecer correlações.

Também foram calculados, conforme Morettin e Bussab (2017): a média, sendo a soma de todos os valores da amostra, dividindo-se pelo número de elementos; desvio padrão que mensura o grau de dispersão do conjunto de resultados em torno da média; mediana, sendo o valor da variável que separa ao meio o conjunto de observações da amostra ou população em dois subconjuntos: um com os maiores valores e outro com os menores valores atribuídos a variável analisada. Trata-se do valor que se encontra no meio de um

\footnotetext{
3 Uma variável binária (variável dummy) pode representar dois estados possíveis: o, ausência da característica de interesse (Fracasso) 1, presença da característica de interesse (Sucesso), de forma que possam ser aproveitadas para a análise estatística (MAIA, 2017).
} 
conjunto de dados e moda que é o resultado mais recorrente de um conjunto de dados. Os cálculos foram realizados sobre todos os dados existentes, exceto sobre os cursistas sem nenhuma nota e que não participaram da pesquisa de avaliação. Ainda assim para esses cursistas foi possível mapear seus Estados de origem.

Além do tratamento dos dados quantitativos, buscou-se realizar análises qualitativas. Para isso além do levantamento inicial de dados junto aos coordenadores do curso, o relatório final da segunda edição do curso objeto desta pesquisa foi analisado, assim como as respostas dos cursistas às questões abertas constantes na pesquisa de satisfação existente na plataforma e a nós disponibilizada.

\section{$4 \quad$ ANÁLISES}

Com base no relatório final da segunda edição fornecido e em todo o tratamento de dados anteriormente descrito, obtivemos as seguintes informações: na $1^{\text {a }}$ edição concluíram o curso com certificação 136 cursistas e na $2^{\text {a }}$ edição foram 141 cursistas de um universo de 318 participantes.

Foram pontuadas grandes diferenças entre as duas edições em relação ao layout do ambiente, design, acompanhamento e conteúdo. Essas mudanças foram realizadas para corrigir e superar obstáculos da primeira para a segunda edição. Segundo os coordenadores não seria producente uma comparação entre as duas edições por se tratar de cursos diversos.

Com base nesses levantamentos iniciais, foram estabelecidas hipóteses sobre a evasão (40,56\%) e a conclusão com aprovação de menos de 50\% dos inscritos (44,34\%), elencadas no quadro 1.

Quadro 1: Hipóteses

\begin{tabular}{|l|l|}
\hline Hipóteses & Conteúdo \\
\hline H1 & $\begin{array}{l}\text { Atraso para início do curso (duas semanas depois da programação } \\
\text { inicial). }\end{array}$ \\
\hline H2 & $\begin{array}{l}\text { Início do curso nas férias - julho de } 2019 \text { (uma reclamação dos } \\
\text { cursistas). }\end{array}$ \\
\hline H3 & Falta de tempo disponível do professor. \\
\hline H4 & Mudança na rede - governo e troca de equipes. \\
\hline
\end{tabular}

Fonte: Elaborado pelos autores, 2020. 
A despeito de não existirem, segundo os coordenadores da instituição gestora, metas de conclusão e aprovação; é possível inferir que se busca identificar possíveis obstáculos a superar para que as próximas edições tenham melhor índice de aproveitamento.

Como já relatado, a segunda edição do curso para formação de curadores, foi composto por 318 cursistas dos quais: 29 não acessaram a plataforma, restando 289 cursistas; dos 289, 189 realizaram as atividades avaliativas e 100 não. Dos 189, 141 foram aprovados. A pergunta aqui posta propõe lançar luz sobre os fatores que contribuíram para que o referido curso tivesse: 29 desistências iniciais, 100 desistências ao longo do curso. Nos gráficos 2 e 3 são demonstrados por Estado as quantidades percentuais e em números absolutos dos 129 não concluintes. Os percentuais foram calculados considerando a totalidade da amostra de 318 cursistas.

Importante ratificar que não há convênio com o Estado do Ceará, mas exclusivamente com o município de Fortaleza.

Gráfico 2: Percentual de não concluintes por Estado

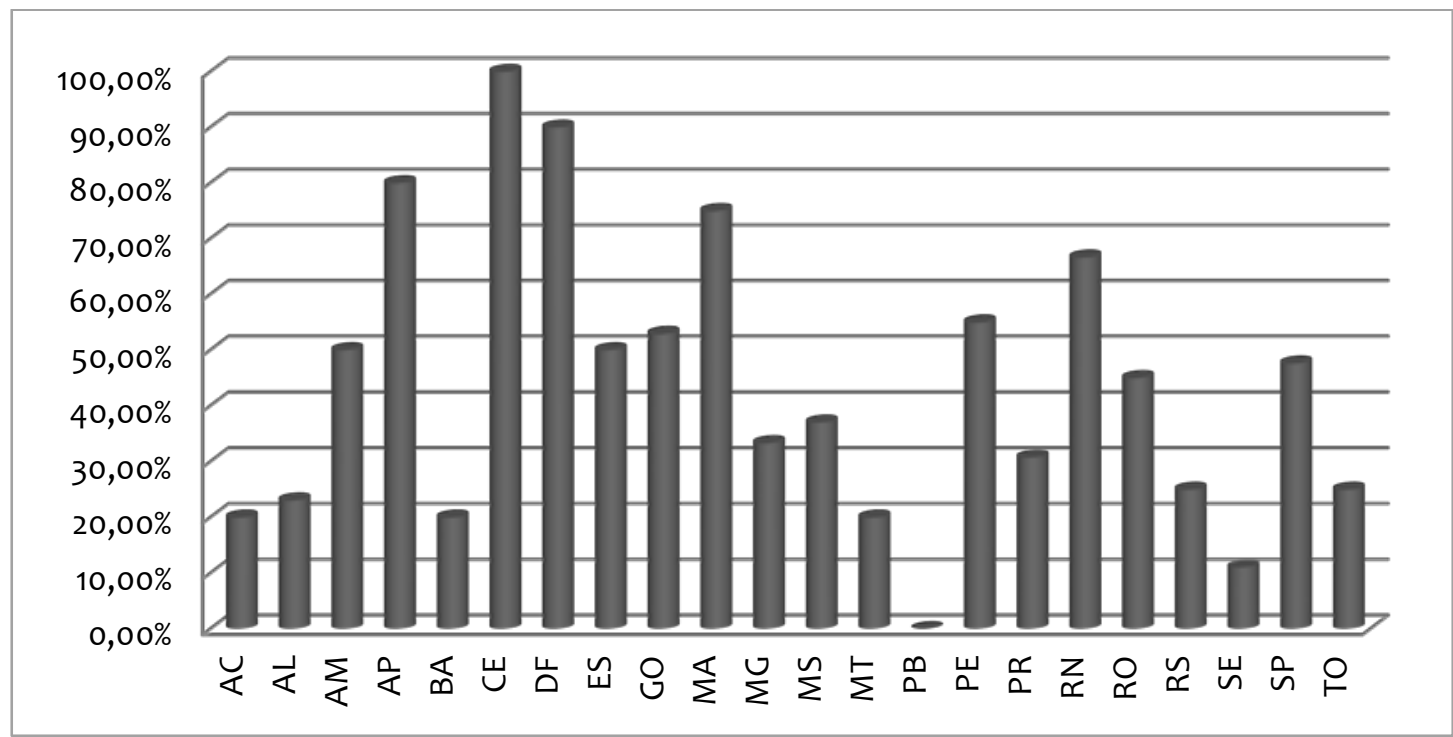

Fonte: Elaborado pelos autores, 2020. 
Gráfico 3: Não concluintes por Estado em números absolutos

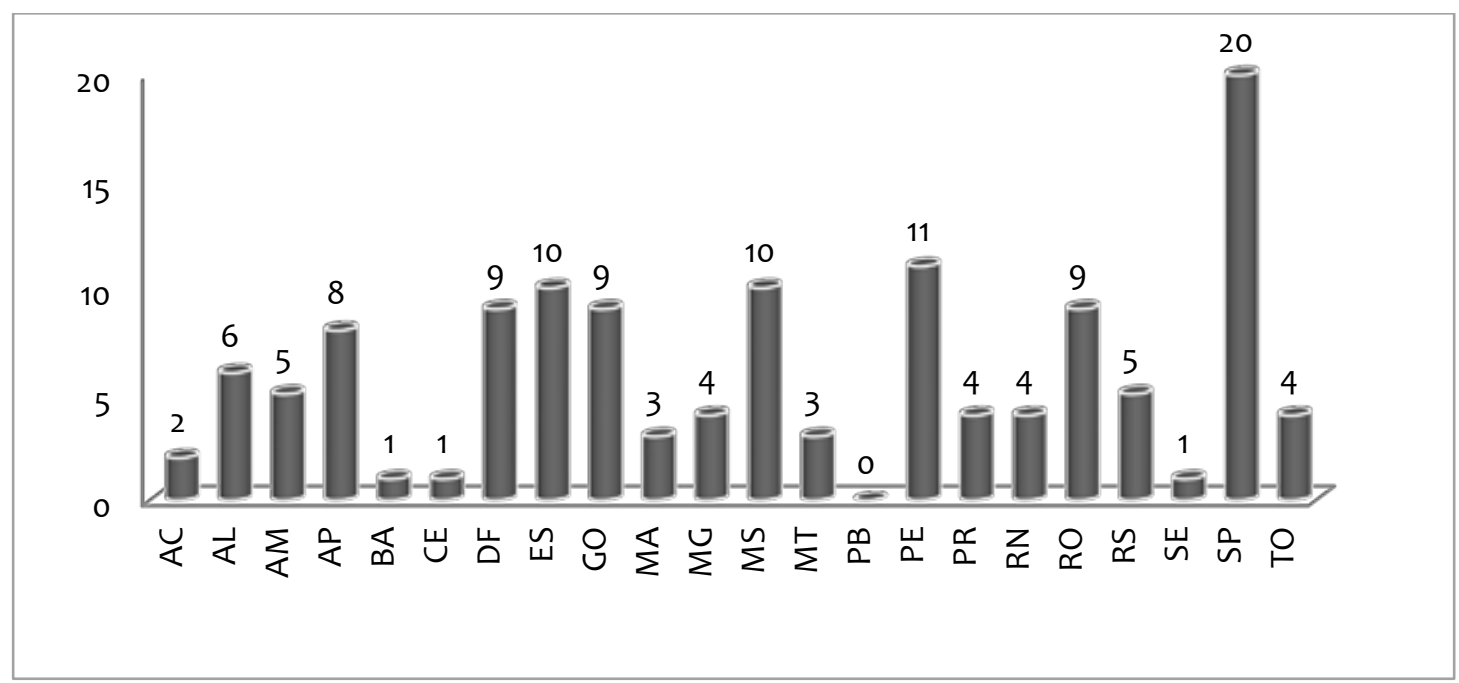

Fonte: Elaborado pelos autores, 2020.

A disparidade de participação de cursistas por Estado subsidia o levantamento de outra hipótese adicional sobre como ocorre à indicação do cursista e seu nivelamento para conseguir participar e se apropriar do que a formação fornece (H5). Entende-se como importante investigar o que ocorreu em Estados como Amapá, Distrito Federal, Pernambuco, São Paulo e Mato Grosso do Sul, para que tivessem um número significativo de cursistas não concluintes, seja em números absolutos ou percentuais. Uma observação importante é que dos 20 cursistas não concluintes em São Paulo, 15 se referem às vagas destinadas ao curso da Faculdade de Educação da universidade selecionada.

Outra hipótese importante é identificar a proximidade e apropriação dos cursistas em relação às tecnologias e aos ambientes virtuais de aprendizagem (H6). Tendo em vista a diversidade dos cursistas inscritos, provenientes de regiões de todo o país. É possível supor que a apropriação do uso de tecnologias também seja um obstáculo a superar dadas as características do curso.

Foi possível estabelecer uma correlação positiva ao analisar a dedicação ao curso que é constituído por vinte e sete atividades, a serem realizadas com diferentes graus de dificuldade. Nessa análise identificou-se que os cursistas aprovados realizaram no mínimo dezesseis atividades dentro das vinte e sete propostas. Na tabela 1, demonstra-se a quantidade de atividades realizadas e a quantidade de cursistas que as realizaram. Dos 318 participantes, 35 realizaram a totalidade das 27 atividades, dos quais cinco foram reprovados. 
Tabela 1: Atividades realizadas $x$ quantidade de cursistas

\begin{tabular}{cccccc}
\hline $\begin{array}{c}\text { Qte Ativ } \\
\text { Realizadas }\end{array}$ & $\begin{array}{c}\text { Qte } \\
\text { Cursistas }\end{array}$ & $\begin{array}{c}\text { Certificado } \\
\text { s }\end{array}$ & $\begin{array}{c}\text { Qte Ativ } \\
\text { Realizadas }\end{array}$ & $\begin{array}{c}\text { Qte } \\
\text { Cursistas }\end{array}$ & $\begin{array}{c}\text { Certificado } \\
\text { s }\end{array}$ \\
\hline 27 & 35 & $86 \%$ & 13 & 2 & $0 \%$ \\
26 & 37 & $86 \%$ & 12 & 10 & $0 \%$ \\
25 & 25 & $80 \%$ & 11 & 5 & $0 \%$ \\
24 & 22 & $68 \%$ & 10 & 6 & $0 \%$ \\
23 & 13 & $100 \%$ & 9 & 9 & $0 \%$ \\
22 & 8 & $75 \%$ & 8 & 7 & $0 \%$ \\
21 & 20 & $65 \%$ & 7 & 6 & $0 \%$ \\
20 & 10 & $60 \%$ & 6 & 8 & $0 \%$ \\
19 & 7 & $14 \%$ & 5 & 8 & $0 \%$ \\
18 & 6 & $33 \%$ & 4 & 6 & $0 \%$ \\
17 & 5 & $40 \%$ & 3 & 6 & $0 \%$ \\
16 & 3 & $33 \%$ & 2 & 11 & $0 \%$ \\
15 & 2 & $0 \%$ & 1 & 6 & $0 \%$ \\
14 & 4 & $0 \%$ & 0 & 31 & $0 \%$ \\
\hline
\end{tabular}

Fonte: Elaborado pelos autores, 2020.

Mesmo realizando todas as atividades, reprovações ocorreram. Ou seja, realizar as atividades somente, não é condição suficiente para aprovação, mas é condição necessária. A despeito desses dados e respectivas análises demonstrados na tabela 1 se reportarem aos cursistas concluintes, é possível inferir que a construção do curso e a apresentação de seus conteúdos, influi nos fatores de evasão $(\mathrm{H} 7)$. Essa questão tem relação direta com a quantidade de horas necessárias de dedicação pelo cursista, abordado a seguir.

O curso é dimensionado para cargas horarias de 40 horas ou 70 horas, a critério do cursista. No guia disponibilizado aos inscritos é indicada uma dedicação necessária de 30 a 60 minutos diários.

A segunda edição transcorreu em um período de oitenta e dois dias corridos (04 de julho a 23 de setembro de 2019), aproximadamente doze semanas.

No relatório fornecido, é apontado que $44 \%$ dos cursistas que responderam a pesquisa, precisaram de até três horas semanais para participar do curso. Nesse mesmo relatório, é possível identificar que $49 \%$ dos respondentes indicaram precisar mais do que quatro horas semanais. Esses dados podem indicar a necessidade de um redimensionamento do tempo e atividades e/ou a necessidade de orientação aos cursistas 
de modo mais contundente sobre a necessidade de auto regulação para a dedicação ao curso e uma conclusão exitosa.

Fica destacado na tabela 2 que há uma correlação positiva entre horas dedicadas, tarefas realizadas e sucesso na aprovação.

Tabela 2: Horas dedicadas semanais

\begin{tabular}{lccc}
\hline & Cursistas & Aprovados & $\begin{array}{c}\text { Média das tarefas } \\
\text { realizadas }\end{array}$ \\
\hline acima de 10 horas & 10 & 9 & 25 \\
entre 8 e 10 horas & 19 & 18 & 25 \\
entre 4 e 7 horas & 46 & 42 & 24 \\
entre 1 e 3 horas & 67 & 48 & 24 \\
menos de 1 hora & 11 & 8 & 22 \\
não declarado & 165 & 16 & 9 \\
\hline Total & 318 & 141 & \\
\hline
\end{tabular}

Fonte: Elaborado pelos autores, 2020.

Em uma análise mais detalhada identifica-se que a participação dos cursistas se desenvolveu de modo oscilante e decrescente ao longo da formação. Os momentos dos cinco fóruns presentes no gráfico 4 (tarefas 3, 7, 11, 20 e 22), deixa claro a queda na participação. Após o fórum do módulo 2, terceiro ponto em declínio (tarefa 11), a participação se estabiliza em um patamar próximo a 55\% dos cursistas realizando as atividades. Houve ainda um pequeno aumento na participação na etapa final do curso. No eixo horizontal estão indicadas as 27 tarefas realizadas durante o curso.

\section{Gráfico 4: Índice de participação nas atividades}

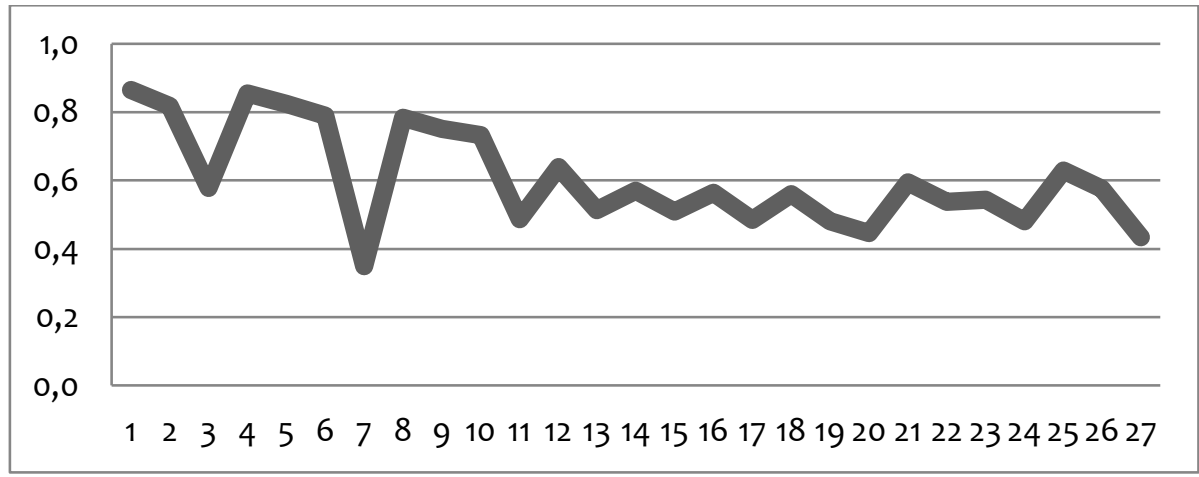

Fonte: Elaborado pelos autores, 2020. 
Realizando uma abordagem mais qualitativa, temos as questões na pesquisa de satisfação disponibilizada ao final do curso, para identificar as avaliações dos cursistas sobre: o curso, seus conteúdos, estrutura, suportes e mediadores; além de questões para auto avaliação. A despeito de ser uma fonte riquíssima de informações, fica prejudicada a visão total pelo fato que o questionário é respondido por aqueles que chegam ao final das atividades, mesmo assim de modo parcial (130 respondentes parciais). O questionário composto por vinte e quatro questões fechadas construídas sobre uma escala Likert, 4 também contou com três questões abertas e uma específica sobre horas dedicadas, já abordadas nesse estudo.

As questões que podiam ter 6 como nota máxima atribuída, receberam avaliações que na média oscilaram de 4,7 a 5,6. E medianas e modas predominantemente iguais a 6. Isso leva a questionar a criticidade dos participantes.

Algumas perguntas e suas respectivas respostas, merecem um maior aprofundamento. A análise da questão 18: "Participei frequentemente do curso lendo e realizando as atividades e postando comentários nos fóruns?", resulta em médias mais baixas principalmente nas turmas 4 e 5 . A questão 19: "Busquei interagir com os demais participantes do curso nos fóruns?" , tem o mesmo comportamento, com as seis turmas se auto avaliando com notas inferiores a cinco.

A questão 23: "Considerei que o meu aproveitamento no curso foi plenamente satisfatório?", demonstra por suas respostas que os cursistas em uma parcela significativa, nas turmas 2, 4 e 5, a despeito de terem finalizado e serem certificados como curadores, não se apropriaram integralmente da formação.

Nas questões que claramente objetivavam avaliar a atuação dos mediadores, que seriam as questões de 09 a 15, observa-se atuações com avaliações relativamente próximas e bem pontuadas. Na turma 2, esse comportamento se difere com avaliações abaixo da média das outras turmas o que pode indicar alguma necessidade de alinhamento. O gráfico 5 aponta como as respostas as 24 questões fechadas foram atribuídas nas seis diferentes turmas.

\footnotetext{
${ }^{4}$ Conforme Junior e Costa (2014), a escala Likert é uma escala de resposta psicométrica usada habitualmente em questionários, e é a escala mais usada em pesquisas de opinião. Ao responderem a um questionário baseado nesta escala, os perguntados especificam seu nível de concordância com uma afirmação.
} 
Gráfico 5: Pesquisa de satisfação

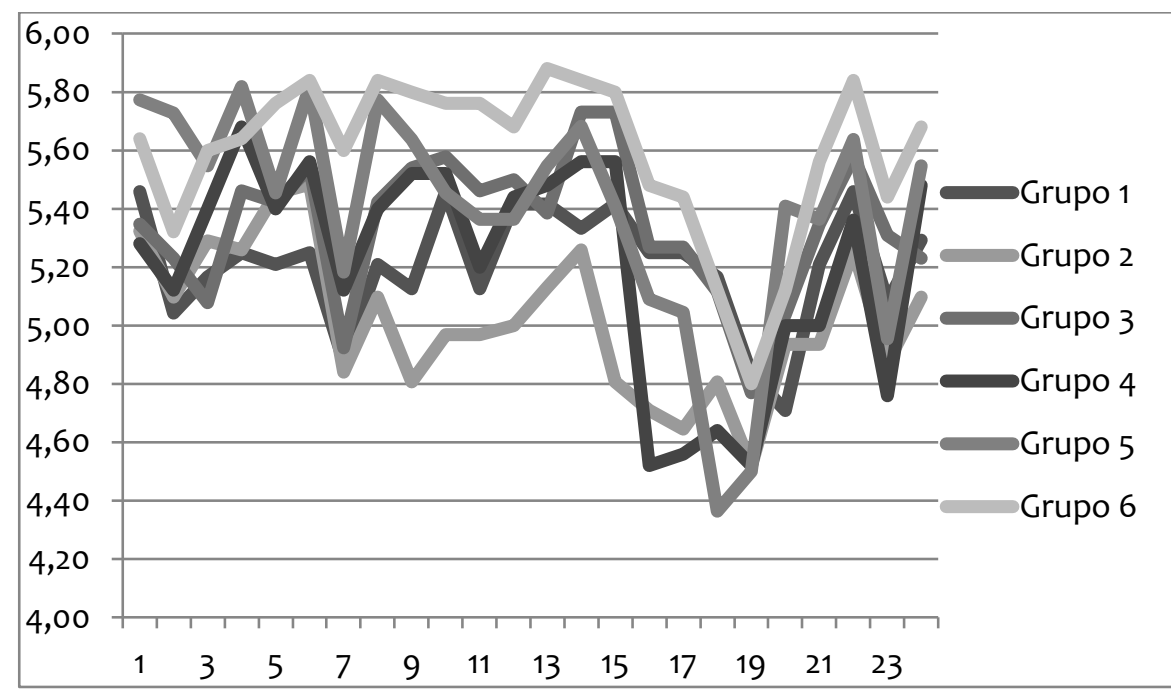

Fonte: Elaborado pelos autores, 2020.

Os cursistas ao responderem sobre o que mais gostaram, destacaram vídeos e as apresentações. Muitos elogiaram o formato disponibilizado e os materiais. Nessa primeira questão aberta à interação, as novas possiblidades e aprendizados foram destacados.

Quando questionados sobre o que mais aprenderam com o curso, a referência aos ODA é relevante. Sobre abordar a curadoria e o quanto compreenderam a importância de ser criterioso, não há referências aos planos de aula. Nessa questão é identificada nas respostas o quanto a tecnologia, e os aprendizados por ela propiciados, estão abrindo novas possibilidades aos participantes do curso.

A última questão aberta que solicita contribuições dos cursistas, se mostra como um insumo de grandes proporções para a melhoria das edições futuras. O comentário mais recorrente é sobre a carga horária e a dificuldade para conciliar a dedicação à formação e as atividades como professores com extensa demanda de trabalho. Muitos indicaram dificuldade para compreender as atividades, principalmente as nos dois últimos fóruns referentes aos módulos 3 e 4 . As críticas ao módulo 4 são repetidas.

Esclarecemos que o citado módulo quatro é o que agrega as atividades avaliativas constituídas por uma avaliação em pares no fórum e pela construção de um mini trabalho de conclusão de curso (TCC) Essas atividades precisavam ser concluídas com média mínima igual a 7,0 para que o cursista fosse considerado aprovado e assim ser certificado. Essas respostas reforçam as hipóteses 3 e 7 . 
Nota-se também os desafios a serem superados em um curso de abrangência nacional e portanto, com ampla diversidade. Um desses desafios era o acesso a internet, que em algumas respostas apareceu como obstáculo, além de dificuldades como converter um arquivo em PDF (Portable Document Format) e anexar documentos, o que se relaciona a hipótese 6.

Em algumas respostas na pesquisa de satisfação foi indicado como positivo a realização de uma Live via Youtube, com a participação de mediadores, coordenadores e cursistas. Nessas respostas aparece a indicação de ampliar esse tipo de estratégia viabilizando comunicação, esclarecimento de dúvidas e interação.

\section{CONSIDERAÇÕES FINAIS E PROPOSITURAS}

A presente pesquisa foi construída em grande parte sobre dados analisados de cursistas que finalizaram o curso. É o caso das informações extraídas da pesquisa de satisfação e também de parte significativa dos dados sobre notas. Assim a análise qualitativa trabalhou sobre os dados dos cursistas que efetivamente participaram do curso e responderam à pesquisa de satisfação. Já as análises quantitativas versaram sobre todos os cursistas, evadidos ou não.

Tendo em vista que o objetivo principal era identificar fatores de evasão, esse foi parcialmente atingido, já que não foi possível acessar em sua totalidade os dados dos cursistas que se evadiram do curso. A despeito desse fato que se mostrou como um limitador da pesquisa, foi possível extrair por meio do discurso dos cursistas e seus indicadores que finalizaram a formação, informações que reportam em parte aos cursistas que evadiram. No quadro 2 relacionam-se as hipóteses construídas ao longo da presente pesquisa.

Quadro 2: Hipóteses

\begin{tabular}{|l|l|}
\hline Hipóteses & Conteúdo \\
\hline H1 & $\begin{array}{l}\text { Atraso para início do curso (duas semanas depois da programação } \\
\text { inicial). }\end{array}$ \\
\hline $\mathrm{H}_{2}$ & $\begin{array}{l}\text { Inicio do curso nas férias - julho de 2019 (uma reclamação dos } \\
\text { cursistas). }\end{array}$ \\
\hline $\mathrm{H}_{3}$ & Falta de tempo disponível do professor. \\
\hline $\mathrm{H}_{4}$ & Mudança na rede - governo e troca de equipes. \\
\hline
\end{tabular}




\begin{tabular}{|l|l|}
$\mathrm{H} 5$ & Indicação do cursista. \\
\hline $\mathrm{H} 6$ & $\begin{array}{l}\text { Não apropriação de habilidades tecnologia e seus recursos pelos } \\
\text { cursistas. }\end{array}$ \\
\hline $\mathrm{H} 7$ & Inadequação da distribuição das atividades, conteúdos e tempos. \\
\hline
\end{tabular}

Fonte: Elaborado pelos autores, 2020.

Para que o objetivo do presente estudo seja totalmente alcançado e suas hipóteses confirmadas ou descartadas, a pesquisa poderia ter continuidade e ser complementada por meio de importantes dados demográficos dos cursistas como formação, área de atuação, idade, gênero, familiaridade com tecnologias e sistemas digitais; que podem agregar fundamentações maiores e melhores para identificar a real apropriação da formação como curador, fatores que contribuem para a não apropriação e possíveis razões para evasão. Esses dados poderiam ser coletados via questionários. Isso se mostra significativo para confirmar ou não a hipótese de que um dos fatores de evasão pode ser a não apropriação de habilidades tecnológicas, que segundo Fullan (2012) indica a necessidade da (re) culturação e reestruturação.

Com a evolução da pesquisa e conforme os achados e dados fornecidos/coletados, a mesma poderá ser desenvolvida e acrescer em tempo futuro para identificar junto aos curadores formados, se a atuação como curador foi concretizada.

Metodologias como análise fatorial exploratória, análise de cluster e Discurso do Sujeito Coletivo (DSC); seriam bem indicadas para apoiar a análise desses dados por meio de instrumento de coleta como questionários estruturados, com questões abertas e fechadas. Para amostras superiores a cem observações, a análise fatorial exploratória se mostra indicada para uma análise mais profunda e melhor validação dos dados.

Conforme Figueiredo Filho e Silva Júnior (2010), a análise fatorial exploratória estabelece a relação entre um conjunto de variáveis identificando padrões de correlação. Essa técnica auxilia em muito nas pesquisas ao buscar identificar e medir variáveis que não podem ser medidas diretamente, mas nas quais é possível identificar os componentes principais que podem ser agrupados em fatores (FIELD, 2009).

Seria importante também incluir na investigação a possibilidade de se identificar com clareza, como os cursistas são indicados em suas respectivas secretarias de educação, já que nesta pesquisa a pergunta sobre como isso ocorre e o quanto o mesmo está realmente 
alinhado com a formação proposta, ficaram sem resposta. Todas essas indicações constituiriam estudos futuros.

A despeito de indicarmos a complementação de dados para a ampliação da pesquisa e a obtenção de resultados, foi possível identificar fatores e construir proposituras com base nos dados e análises realizadas neste estudo.

Fica clara a necessidade de ajustes na construção e estrutura do curso no que diz respeito a conteúdos, propostas de atividades e seus respectivos tempos. Da mesma forma a reculturação dos participantes com relação a aprendizagem por meio do EaD, se mostra primordial.

Indica-se como primeira ação repensar a forma de indicação dos participantes de modo a esclarecer aos mesmos a necessária disponibilidade temporal e as características de um ambiente virtual de aprendizagem. Essa ação poderia ser complementada com o acréscimo na plataforma de pequenos vídeos tutoriais, orientando procedimentos que somados às orientações dos mediadores, trariam maior conforto aos cursistas que ainda estão se apropriando de ferramentas tecnológicas.

Outro ponto importante é a estruturação da evolução do curso em suas atividades aumentando de modo gradativo e equilibrado, o volume de conteúdo e seu nível de complexidade. Isso pode mitigar a percepção dos cursistas de um aumento de dificuldades abrupto, e que pode motivar as respectivas desistências como demonstrado no gráfico 4.

Fica aqui como mais uma propositura, a reformulação da pesquisa de satisfação, pois em algumas questões não fica claro para o respondente sobre qual atuação se está perguntando: a do mediador, a do curso ou outra. As questões 7, 16 17, são exemplos dessa ocorrência.

Conforme censo 2017 (ABED, p.7, 2018), o índice de evasão do curso para formação de curadores indica um índice significativo: "As taxas de evasão da EAD ainda são superiores aos cursos presenciais, mas temos $5 \%$ do total de instituições com taxas entre o e $5 \%, 5 \%$ das instituições com taxas entre 6 e 10\%, e somente $1 \%$ das instituições registraram taxas de mais de $50 \% "$

A proposta de investigação, então, se mostra útil na medida que pode contribuir para a redução desse índice com uma maior efetividade na formação e ampliação da rede de curadoria. 
Concluindo, as possíveis causas para a evasão são decorrentes de diversos fatores como apontado por Santos e Neto (2009). Os pontos abordados no presente estudo vêm ao encontro, dentro do que foi possível extrair, especificamente do que York e Longden (2004) e Xenos, Pierrakeas e Pintelas (2002) apontam como fatores influenciadores para a evasão de um curso, sejam eles relacionados aos alunos, ao curso, aos mediadores ou ainda fatores sócio demográficos; cada um com seu nível de importância e potencial de influência. Como bem destacado por Jesus e Maciel (2015) e por Pinotti (2010), são novas configurações e reconfigurações no processo de formação profissional.

\section{REFERÊNCIAS}

ABED. Associação Brasileira de Educação a Distância, 2017. Disponível em: http://abed.org.br/arquivos/CENSO_EAD_BR_2018_digital_completo.pdf.Acesso em: 14 nov. 2019.

BOKUMUS, Raquel Maia; MAIA, Jusselma Ferreira. Educação a Distância (EaD) no Brasil: uma reflexão a respeito da inclusão social. Diálogo, v.38, p. 99-111, 2018. Disponível em: https://revistas.unilasalle.edu.br/index.php/Dialogo. Acesso em: 02 nov. 2019.

BRASIL. Ministério da Educação. Lei Federal no. 9.394, de 20 de dezembro de 1996. Estabelece as diretrizes e bases da educação nacional. Disponível em: http://www.planalto.gov.br/ccivil_03/LEIS/l9394.htm. Acesso em: 14 nov. 2019.

BRASIL. Ministério da Educação.. Decreto Federal no. 5.622, de 20 de dezembro de 2005. Regulamenta o art. 80 da Lei no. 9.394, de 20 de dezembro de 1996, que estabelece as diretrizes e bases da educação nacional. Disponível em: http://www.

planalto.gov.br/ccivil_03/_Ato2004-2006/2005/Decreto/D5622.htm Acesso em: 14 nov. 2019.

CAPES. Portal de Periódicos da Capes. Disponível em: http://www-periodicos-capes-govbr.ez95.periodicos.capes.gov.br/. Acesso em: 02 nov. 2019.

CHIZZOTTI, Antonio. Pesquisa em ciências humanas e sociais. 12 ed. São Paulo: Cortez, 2017.

CHIZZOTTI, Antonio. Pesquisa qualitativa em ciências humanas e sociais. 6 ed. Petrópolis: Vozes, 2018.

COELHO, Maria de Lourdes. A Evasão nos Cursos de Formação Continuada de Professores Universitários na Modalidade de Educação a Distância Via Internet. Universidade Federal de Minas Gerais, 2002. Disponível em: http://www.abed.org.br/congress02001/02.zip. Acesso em: 04 nov. 2019.

CRESWELL, John W. Investigação Qualitativa e Projeto de Pesquisa: Escolhendo entre Cinco Abordagens. Porto Alegre: Penso Editora, 2014. 
FIELD, Andy. Descobrindo a estatística usando o SPSS-2. Porto Alegre: Bookman Editora, 2009.

FIGUEIREDO FILHO, Dalson Brito; SILVA JÚNIOR, José Alexandre da. Visão além do alcance: uma introdução à análise fatorial. Opinião Pública, v. 16, n. 1, p. 160-185, 2010. Disponível em : http://www.scielo.br/scielo.php?pid=S0104-

62762010000100007\&script=sci_arttext\&tIng=pt. Acesso em: 02 nov. 2019.

FULLAN, Michael. Change forces: Probing the depths of educational reform. Abingdon, Inglaterra, UK: Routledge, 2012.

HOLDER, Bruce. An investigation of hope, academics, environment, and motivation as predictors of persistence in higher education online programs. Internet and Higher Education, v.10, p. 245-260, 2007. Disponível em:

http://anitacrawley.net/Resources/Articles/Holder.pdf. Acesso em: 12 nov. 2019.

JESUS, Dánie Marcelo de. Reculturação, Reestruturação e Reorganização Temporal de Professores no Ambiente Digital. Tese de Doutorado em Lingüística Aplicada e Estudos da Linguagem. 221 f. LAEL, PUC, São Paulo, 2007. Disponível em: https://tede.pucsp.br/bitstream/handle/13910/1/Danie\%20Marcelo\%20de\%20Jesus.pdf. Acesso em: 12 nov. 2019.

JESUS, Dánie Marcelo de; MACIEL, Ruberval Franco. (Orgs.). Olhares sobre tecnologias digitais: linguagens, ensino, formação e prática docente. Campinas: Pontes, 2015.

JÚNIOR, Severino Domingos da Silva; COSTA, Francisco José. Mensuração e escalas de verificação: uma análise comparativa das escalas de Likert e Phrase Completion. PMKTRevista Brasileira de Pesquisas de Marketing, Opinião e Mídia, v. 15, n. 1-16, p. 61, 2014. Disponível em: http://sistema.semead.com.br/17semead/resultado/trabalhosPDF/1012.pdf. Acesso em: 07 mai. 2020.

LITTO, Fredric M. Fechamento de mais de 1000 polos educacionais, 2008. Disponível em: http://www.abed.org.br/site/pt/midiateca/clipping_abed/885/2008/12/frederic_m._litto_fa la_sobre_o_fechamento_de_mais_de_1000_po- los_educacionais. Acesso em: 14 nov. 2019 .

MAIA, Alexandre Gori. Econometria: conceitos e aplicações, 2017. Disponível em: http://www4.eco.unicamp.br/docentes/gori/images/arquivos/Econometrial/Econometria VariaveisBinarias.pdf. . Acesso em: 10 nov. 2019.

MICHAELIS. Dicionário on-line. 2011. Disponível em: http://michaelis.uol.com.br/. Acesso em: 28 nov. 2019.

MORAN, José Manuel; VALENTE, José Armando. Educação a distância. Summus Editorial, 2015. Disponível em:

https://www.researchgate.net/profile/Jose_Moran5/publication/228846830_O_que_e_ed 
ucacao_a_distancia/links/5539133docf247b8587fc8c9/O-que-e-educacao-a-distancia.pdf. Acesso em: 14 nov. 2019.

MORETTIN, Pedro Alberto; BUSSAB, Wilton Oliveira. Estatística básica. São Paulo: Editora Saraiva, 2017.

NUNES, Ivônio Barros. Noções de Educação a Distância, 1992. Disponível em: http://www.intelecto.net/EaD/. Acesso em: 14 nov. 2019.

OKOLI, Chitu; DUARTE, Traduzido por: David Wesley Amado; MATTAR. Guia Para Realizar uma Revisão Sistemática de Literatura. EAD EM FOCO, [S.I.], v. 9, n. 1, abr. 2019. ISSN 21778310. Disponível em: http://eademfoco.cecierj.edu.br/index.php/Revista/article/view/748. Acesso em: 08 out. 2019.

PINOTTI, Sandra Sisuka Matsubara. Desafios dos processos de reculturação, reestruturação e reorganização temporal de práticas pedagógicas em ambiente virtual. Dissertação (Mestrado em Estudos de Linguagem). 118 f. Instituto de Linguagem.

Programa de Pós Graduação em Estudos de Linguagem, Universidade Federal de Mato Grosso - Cuiabá (MT), 2010. Disponível em:

https://www1.ufmt.br/ufmt/unidade/userfiles/publicacoes/cba42e5f5818ea7c6a8745dc274 932ee.pdf. Acesso em 12 nov. 2019.

SANTOS, Elaine Maria dos; NETO, José Dutra de Oliveira. Evasão na Educação a Distância: identificando causas e propondo estratégias de prevenção. Revista Paidéi@, UNIMES VIRTUAL, v. 2, n. 2, dez. 2009. Disponível em: http://revistapaideia.unimesvirtual.com.br. Acesso em: 12 nov. 2019.

SHANNON, G. Sue; BYLSMA, Pete. Helping Students Finish School: Why Students Drop Out and How to Help Them Graduate. Office of Superintendent of Public Instruction, Olympia, WA, 2006. Disponível em: https://files.eric.ed.gov/fulltext/ED498351.pdf. Acesso em: 04 nov. 2019.

TRESMAN, Susan. Towards a Strategy for Improved Studenty Retention in Programmes of Open, Distance Education: A Case Study from the Open University UK, 2002. Disponível em: file:///Users/anavaleria/Downloads/75-Article\%20Text-1443-2-10-20101020\%20(1).pdf.

Acesso em: 04 nov. 2019.

XENOS, Michalis.; PIERRAKEAS, Christos; PINTELAS, Panagiotis. A survey on student dropout rates and dropout causes concerning the students in the Course of Informatics of the Hellenic Open University. Computers \& Education, v. 39, n. 4, p. 361-377, 2002. Disponível em:

https://www.sciencedirect.com/science/article/abs/pii/S0360131502000726. Acesso em: 04 nov. 2019.

YORKE, Mantz.; LONGDEN, Bernard. Retention and Student Success in Higher Education. Open University Press. McGraw - Hill Education, 2004. 
Recebido em: 10/07/2020

Parecer em: 08/10/2020

Aprovado em: 15/03/2021 